\section{Disallowing direct costs}

SIR - The recent concern over indirect cost recovery at US universities is wellfounded, but researchers should be warned there may be a more ominous shakeup if government auditors decide to take a stricter stand on the allowability of direct costs.

Direct line-item expenditures are approved by government agencies when research proposals are accepted for funding, and as such are implicitly considered allowable. But when the time comes actually to purchase equipment, pay salaries or procure services, researchers are constrained by a baroque set of government regulations (the Federal Acquisition Regulations) that are applied and often interpreted differently by each funding agency. Auditors can (and do) disallow certain direct costs when investigators or their institutions fail to

\section{Continental drift}

SIR - Alan Goodacre (Nature 354, 261; 1991) brought to mind something I read a few weeks ago in an anthology of geographical and travel literature texts (Der Deutsche in der Landschaft, ed. R. Borchardt, Insel Taschenbuch it 1218, p. 163, Frankfurt, 1989) which reads in translation:

One cannot help thinking of a real and earlier coherence between Arabia and its neighbouring countries in the East and the West, tracing on the map the trapezoidal outline of this peninsula, which appears to be a fragment, separated by the narrow, parallel gaps of the Persian and Arabian Gulfs. Fragmented at a time when the levels of the crust, already cooled down or dried off and lifted up, floating on a more mobile substrate, were not yet fixed as they are today, and therefore whole systems of the landsurface could break loose, while the gaps were filled with water, forming straits.

This was written by Carl Ritter in Die Erdkunde im Verhälniss zur Natur und zur Geschichte des Menschen Wissenschaften Vol. 1, 62 (2nd edn, Berlin, 1832). The fact that this is the second edition makes it possible that the same thoughts had been set down and printed even earlier, but I do not have access at present to the first edition. As can be seen from the text, the row between Plutonist and Neptunist had not yet been resolved, which probably hampered the general acceptance of such ideas for a long time. It took more than 150 years to collect the evidence to support the theory of continental drift, which in turn requires it to explain the data.

W. EBERHARD FALCK Ismes SpA, Via dei Crociferi 44, I-00187 Roma, Italy

\section{follow these rules.}

For example, an overseas trip paid for with Department of Energy contract funds may be disallowed if the principal investigator fails to file a pre-trip approval request 90 days in advance and a trip report upon his or her return to the United States - even if the trip was included in the investigator's original proposal. The same trip can be made on a National Science Foundation grant without prior approval. Bizarre reporting requirements are often buried deep in the middle of grant and contract documents, and some agencies make only a reference to applicable regulations without including the actual text in their award notifications.

As a former grant and contract negotiator for a major US university, I can say with confidence that most researchers are not familiar with funding agency regulations, nor are most of their institutions capable of ensuring full compliance.

Arguably, it is the responsibility of research administrators to ensure that principal investigators (PIs) and laboratory directors to understand the conditions of their awards. Similarly, university accounting offices and internal audit departments are supposed to discover and correct unallowable expenditures before the feds do. But in practice, few universities are able to do any of this adequately. Some of the burden of compliance inevitably fails on the PI. PIs, however, have little incentive or time to slog through endless pages of bureaucratic legalese to find out what they can and cannot do. The result is that direct cost disallowances may well become a major concern as attention is focused ever more closely on the way universities spend government money.

BRADFORD J. HURLEY

313 Commonwealth Avenue,

Concord, Massachusetts 01742, USA

\section{Correcting errors}

SIR - Over the past decade, I have encountered serious difficulties in correcting errors in the work of others (see, for example, my report in J. Chem. Educ. 68, 474; 1991). My observations follow. There are (1) authors who are unwilling to publish Errata to their proven errors; (2) (internal) barriers to publication of explicit comments on errors in the work of others; and even (3) some authors who, when asked to function as referees, obstruct publication of a paper correcting their own errors. In my opinion, Ethical Guidelines to Publication of Chemical Research (Acc. Chem. Res. 18, 355; 1985) may not sufficiently respond to these situations.

Because it is important that the published record should be as accurate as possible, I propose that the following rules should be adopted by the scientific community and by journals: (1) errata may be published by persons other than the original authors; (2) authors who prefer to correct serious errors in the published papers of others in the text of their own original articles should cite in the abstract the source of the errors being corrected; and (3) in the case of an article correcting errors, the author(s) of the errors should never be selected as anonymous referees (although, of course, their right of a possible response to a published criticism would still apply).

\section{Limburgs Universitair Centrum}

ZDENEK SLANINA*

\section{Department $S B G$}

\section{B-3590 Diepenbeek, Belguim}

Permanent address: Czech Academy of Sciences, Prague, Czechoslovakia.

\section{Fermi's mistake?}

SIR - Your cover of 2 January 1992 may give the widest publicity yet to one of the minor mysteries of physics or physicists. The left oval shows Enrico Fermi at his blackboard, a scene also used in "The World of Enrico Fermi", a 1970 Project Physics film. Above his head appears in Fermi's clear script the definition for $\alpha$, the "fine structure constant" of atomic physics, but it is clearly, shockingly wrong. Every physicist learns early that $\alpha=\left(\mathrm{e}^{2} / h \mathrm{c}\right)$ or about $1 / 137$, and Fermi had lived with $\alpha$ for at least 35 years.

I was shocked on glimpsing this anomaly when I saw the film; it turns out that Norman F. Ramsey, professor of physics at Harvard University, had long ago noted this error and was equally puzzled by it.

The problem is that $\alpha$ is a dimensionless quantity, known by rote to every physicist, in form and value. It is the ratio of the orbital velocity of the electron in the hydrogen atom to the speed of light, for instance. The anomaly on the blackboard is not dimensionless, is bigger the smaller is the electric charge $\mathrm{e}$, and it is difficult to believe that Fermi could have written it, even under the (by then not unfamiliar) stress of being photographed for posterity.

The most probable explanation is that Enrico Fermi, a great physicist, both in theory and experiment, and a man full of fun and humour, was having a little fun with the photographer.

IBM Research Division,

RICHARD L. GaRWIN

Thomas J. Watson Research Center,

PO Box 218,

Yorktown Heights,

New York 10598-0218, USA 